\title{
Editorial
}

\section{Building Partnerships in an Educational Ecosystem}

The field of education is facing enormous pressures. Changes in societies, knowledge, and work are a reality in Europe as well as across the globe. The Council of the European Union (2014, p. 22) has noted:

In a fast changing world, the role of teachers - and the expectations placed upon them - are evolving too, as they face the challenges of new skills requirements, rapid technological developments and increasing social and cultural diversity, and the need to cater for more individualised teaching and special learning needs.

In order to improve education in the future, it is important to develop and implement strong partnerships (The European Council, 2014). Teacher education is expected to foster cross-disciplinary and collaborative approaches so that educational institutions and teachers understand that part of their task is to cooperate with relevant stakeholders, such as colleagues, parents, and employers. The European Council sets high standards for teacher educators and teacher education programmes; it expects them to respond to societal changes and improve the quality of education for different types of learners. The Council of the European Union (2014) emphasises that high-quality teaching is needed for learners to realise their full potential, both as individuals and as active members of society and as contributors to the workforce.

Teachers and teacher education play a key role in ensuring high-quality learning outcomes. However, they are only part of a bigger picture that is continuously changing. As Hargreaves described in the 1990s, that picture is a moving mosaic. In a complex world, many different parts are interconnected and interdependent. Teacher education and teachers' work happen in collaboration with many partners. Building a partnership is not a one-sided process in which communication only flows in one direction. Rather, it is a multi-faceted process with many changing contexts.

Building partnerships in education is the focus of the articles in this journal's current edition. It was the main theme at the conference of The Teacher Education Policy in Europe (TEPE) in 2015 in Dundee, Scotland. The Center for Educational Policy Studies Journal (CEPS Journal) announced a call for papers on this topic and invited conference participants and people working in and with the field of teacher education to submit articles. TEPE is an academic network that brings together educational researchers, policy makers, teachers, and practitioners from Europe and also often from other countries globally. 
Annual conferences provide an opportunity to reflect on the year's theme from different angles. The 2015 conference explored the opportunities and challenges of building partnerships within and across teacher education policies and practice. Toward that end, it encouraged discussions on the following themes:

- $\quad$ Building Partnerships with Schools

- Building Partnerships with Local Authorities

- $\quad$ Building Partnerships with Policy Makers

- Building Partnerships in Teacher Education

Therefore, this edition of CEPS Journal aims to analyse and reflect upon how, and under what conditions, partnership in education can be created and implemented. This issue of the journal also aims to address the barriers that impede cooperation and identify the areas where cooperation is most needed. While partnership is a commonly used concept in recent political discourse, what is missing is a deeper reflection on what partnership requires from different partners and what kinds of conditions are needed to build and sustain it. A general meaning of partnership links it with concepts of cooperation, sharing, and joint aims. Building partnerships in education requires collaboration and cooperation on several levels: global, national, institutional and personal. At times, partnership can include all these levels, and, in some cases, it can focus on specific connections.

Partnership can be viewed from the perspective of a system and how different parts of that system are interconnected. In addition, a sociological framework is a central concept in the learning sciences. From the perspective of learning research, we can see the trend towards more cooperation and cocreation that can also be understood as partnership. Increasingly, learning is being seen as a process that is based on sharing and participating with different partners in a learning society. Social perspective theorists reject the traditional information-processing view that posits that knowledge is acquired by transmission from one knower to another, and then represented solely within the mind of the knower. Rather than use the terms 'acquisition' and 'representation', social perspective theorists view knowledge as 'construed by' and 'distributed among' individuals and groups as they interact with one another and with cultural artefacts, such as pictures, texts, discourse, and gestures. Knowledge is not an individual possession; rather, it is socially shared, and it emerges from participation in social activities (Reynolds, Sinatra \& Jetton, 1996; Cole, 1991).

Recently, the ecosystem concept has emerged in many disciplines. Partnership and ecosystem concepts are frequently seen as being parallel or even synonymous. The ecosystem concept is used in several disciplines or discourses. We can see it being used in discussions on business ecosystems, innovation ecosystems, education ecosystems, health care ecosystems and service ecosystems. The 
Collins English Dictionary defines that "an ecosystem is all the plants and animals that live in a particular area together with the complex relationship that exists between them and their environment" and Dictionary.com gives a more general meaning, stating that "any system of interconnecting and interacting parts". The ecosystem concept has been increasingly used in the fields of medicine and health care. Walpole et al. (2016) advocated that human health is fundamentally determined by the health of ecosystems. They claim that guidance is lacking about how to address the topic of ecosystems within medical education. The same kind of opinion can be heard in the field of veterinary medicine.

Schwind et al. (2016) suggested the need for a transdisciplinary approach through which organisations promote cooperation and collaboration among humans, animals, plants and ecosystem health sectors and professionals. That understanding of ecosystems acknowledges that the health of each sector is dependent upon the health of the other sectors (Kahn et al., 2012).

The ecosystem concept has its roots in biology, where typical ecosystems are a forest, a pond, and grassland. The most important feature of an ecosystem is the interconnectedness of its constituents. Species closely interact with one another to survive. They are interdependent, and information flows throughout the system, both of which are basic conditions for survival. While warmth, water, and energy sources all contribute to the ecosystem, the system does not function well without interconnectedness.

The ecosystem concept has recently been expanded to include more human contexts, especially social structures. The systems of human actors or companies and organisations can also be described as ecosystems. The term 'innovation ecosystem' refers to a dynamic, interactive network that breeds innovation. In practice, the term can refer to local hubs, global networks, or technology platforms (Moore, 2006). According to Oksanen and Hautamäki (2015), an innovation ecosystem is a network of relationships through which information and talent flow through systems.

A high level of interconnectedness and interdependence and the flow of information are the most important features of the ecosystem concept. Mars, Bronstein and Lusch (2012) analysed the value of this concept, noting that the metaphor inherent in this concept had provided a fresh lens through which to view a dramatically altered world. However, they also had some caveats. Biological ecosystems involve separately functioning compartments that are linked by flows of resources and information. While the ecosystem metaphor is a useful tool for understanding and predicting the conditions that shape and influence organisational systems, its appeal to business leaders and scholars has, in large part, been based on one central misguided assumption: that biological 
ecosystems are both communal (supported by individual commitments to the greater good) and stable. Biological ecosystems emerge, function and collapse organically, without the aid or intervention of purposefully designed strategies and structures. Ecosystem engineers create and modify habitats upon which other species rely. If key actors are harmed or removed from ecosystems, failure becomes highly likely. Human organisations can design and plan systems and networks. Human engineers (actors) may create conditions that can, potentially, have an impact beyond the local setting. Humans have the ability to adapt and replicate innovations, which expands the impact of human engineering across multiple settings.

Niemi et al. (2014) noted that an educational ecosystem has complex connections and processes that interact with different levels of society and different social structures. We can refer to a macro-level ecosystem when different levels or sectors in a society and the educational system work together. On its own, education cannot create the future. It must establish connections with other sectors, including health care, housing, business, and working life. However, educational ecosystems also have meso- or mid-level units that consist of structures and social practices at the institutional and community levels (e.g. universities, other higher education institutions, schools) that can create a sharing and cooperative culture. In discussions about successful organisations, it seems that a commitment to joint aims and a shared culture are critical. In education, we can also observe micro-level ecosystems, where individuals are learning and creating knowledge and are, then, influenced by characteristics, such as prior knowledge, skills, motivation and attitudes, which represent the learner's cultural background, as well as interactions with other people and artefacts (Säljö, 2010, 2012; Vygotsky, 1978). Thus, an educational ecosystem consists of a large number of interconnected parts, both horizontally and vertically.

We can learn from earlier studies (e.g. Walpole 2016; Scwind, 2016) that the health of an ecosystem is based on interconnectedness and information flow (meaning communication in human relationships). The system functions well when its different parts work together. However, in reality, that is not always true. Ecosystems can have serious dysfunctions and imbalances, often in natural environments impacted by human actions as we have learned from the many reports on climate change. The same is true for educational ecosystems. In different sectors, partners and actors are not interconnected. They do not share information, resources or aims; tension can thus arise. Moreover, cultural practices may also separate one part of the system from another.

Many sociologists, notably Habermas (1987), have described how systems in a modern society can be separated from each other and can become 
colonized through hierarchy and lack of communication. As in society, so in education; the subsystems can become separated into segmented territories with their own aims, social practices, and power structures; eventually, collaboration between the parts vanishes.

An educational ecosystem is not a stable system. In contrast to a biological system, an educational ecosystem needs human actors, and it is dependent upon conscious human behaviour. For an educational ecosystem to be sustainable, its participants must intentionally share joint aims and take action to ensure interconnectedness, interdependence, and open and transparent mutual communication between all partners. In complex and moving systems, many of the components undergo their own change processes, and this information needs to be analysed, updated and shared when working towards common goals. Interaction and communication with the flow of information are basic conditions for maintaining commitment from partners. When referring to partnerships in education, we have to acknowledge that collaborators must set an intentional aim to ensure that the ecosystem works to realise joint goals and objectives. 'Partnership' means human action that promotes interconnectedness and communication.

The theme of the current edition of CEPS Journal is building partnership in education. The articles describe how partnership has been promoted in different European countries and in different forums. In the articles, we can see that achieving connectedness and communication does not happen without tension and contradictions.

This issue of the journal begins with a discussion paper written by Kari Smith, "Partnerships in Teacher Education - Going beyond the rhetoric with reference to the Norwegian context". This paper was originally given as a keynote lecture at the TEPE Conference. Its main message is that partnership should go beyond rhetoric. Responsibility for education lies with a number of people, including stakeholders, policy makers, researchers, teacher educators, teachers, and parents. Teacher education is placed in the middle of the many complex relationships that exist between the various stakeholders. For partnerships to go beyond rhetoric and for the partners to strive to truly work together to achieve a shared goal, several challenges must be overcome. The partners should trust each other and be open to listening to and accepting different opinions and solutions. In reality, a partnership involves risks, especially when the aim is to develop an idea or to go beyond the comfort zone of all the partners; this process can be time-consuming. There will be successes as well as relapses, and Smith suggests that it is important to establish clear agreements about how to share power and responsibilities. Smith reflects on the tensions that often 
emerge in partnerships. Working in a team and seeking consensus to enable progress may be challenging. Partners often represent different cultures, but this can also be mutually beneficial. Often different kinds of expertise are necessary to achieve the shared goal. Smith suggests that partners should be open to and respect each other's expertise, and also see value in it for the common interest. Smith also introduces Halvorsen's study in the Norwegian context in which four different resources - intentionality, unpredictability, flexibility, and vitality - can be found when promoting cooperation between teacher education institutions and teacher practice in the field. Practice is an important part of teacher education, and it requires universities and local schools to engage in a high level of collaboration and establish shared aims. Smith also describes the main principles of a new cooperative model for partner schools and teacher education institutions in a Norwegian context.

The second article, "The Discourse of Partnership and the Reality of Reform: Interrogating the Recent Reform Agenda at ITE and Induction Levels in Ireland", by Judith Harford and Teresa O'Doherty, provides an Irish context. In their paper, Harford and O'Doherty describe the role that the Teaching Council plays in teacher education reform. That Council is the statutory body in Ireland that is responsible for regulating the teaching profession. In that country, universities and colleges had exercised high levels of institutional autonomy in relation to the content and nature of teacher education programmes with little state intervention or regulation. This situation changed considerably in 2006 when teacher education was impacted by state intervention and regulations. Now, all teacher education programmes in Ireland must be rigorously reviewed and professionally accredited by the Teaching Council. A significant problem with this change has been that it has instituted one-sided communication and regulation as top-down processes. Harford and O' Doherty describe an example of how a shift from 'teaching practice' to 'school placement' was announced by the Teaching Council. The Council did not consult with Initial Teacher Education (ITE) providers, schools or teachers before publishing its guidelines. The ITE providers had full responsibility for implementing the policy shift. The unbalanced communication resulted in a breakdown of interconnectedness, but it also stretched resources to a very critical point. Schools, teachers, and teacher educators were expected to respond to requests on a goodwill basis that is unsustainable in the long-term. Another case of one-sided regulation is related to the introduction of a revised induction/probation process. The Council's decision imposed an additional burden on teachers in terms of out-of-school time and administration. It also eroded the traditional collegiality of schools by requiring teachers to assess their peers at a time when teachers as civil servants 
are hardest hit by national budgetary cuts. In summary, Harford and O'Doherty note that the rhetoric of partnership, and the absence of the Council's willingness to value real partnership and to support it appropriately, has drained the goodwill of Irish teachers. Through an analysis of key policy documents, this paper argues that partnership can be valorised. If a partnership metaphor has been loosely employed, it denotes consensus and collaboration.

The third article, "Scenarios of Mentor Education in Romania - Towards Improving Teacher Induction", by Mihaela Stîngu, Eve Eisenschmidt, and Romiță Iucu describes how to organise induction for newly qualified teachers by training high-quality mentors. These Romanian researchers worked in partnership with Estonian teacher educators to find models for Romania. In Estonia, a teacher induction programme has been in place for more than ten years. In contrast, in Romania, teacher induction is relatively new and has only been mandatory since 2011. The need to support new teachers is an urgent issue in both countries, and training mentors is a key issue for a successful and sustainable teacher induction programme. In Estonia, a mentor teacher supports socialisation, provides emotional support and fosters the novice teacher's professional development and learning through dialogue and reflection. The mentor courses see schools as learning organisations. Thus, mentoring is viewed as a partnership between a mentor and a new teacher. However, a mentor plays a specific role; to grow into this role, s/he needs well-organised training. This paper proposes two possible scenarios for the Romanian system; in one, the mentor training is part of academic master and doctoral education, and in another, it is part of more flexible short-term in-service education. The advantages and disadvantages of both models are addressed in this article. Ultimately, the paper proposes that a flexible, needs-driven system, which encompasses a degree of choice, will best fulfil the professional development of teachers who wish to become mentors. Both countries and their educational systems see that induction is a very important phase in a teacher's professional development, but a model cannot be transferred directly from one country to another. Stîngu, Eisenschmidt, and Iucu suggest that discussions about mentoring in Europe are needed. We should identify how schools as organisations can support novice teachers and mentoring within the school context, and determine how to create a collaborative culture to support newcomers. At the macro level (national and European levels), they propose more discussion about how to select mentors and organise their workload and how to arrange for mentor education.

The fourth article, "Newly Qualified Teachers' Needs of Support for Professional Competence in Four European Countries: Finland, the United Kingdom, Portugal and Belgium", by Vilhelmiina Harju and Hannele Niemi, is related 
to the European Erasmus+ programme about which the authors have collected data. The first few years in the teaching profession are demanding. Although initial teacher education forms an essential base for a teacher's work, it cannot fully prepare new teachers for the complexities of schools in a changing world. This study focuses on investigating the needs of support for professional development among newly qualified teachers from four different countries: Finland, the United Kingdom (England), Portugal and Belgium (Flanders). The results indicate some of the most urgent areas that should be addressed in all four countries. New teachers need support and mentoring so they can learn how to handle situations in which conflicts arise, such as bullying in schools. They also need support for how to differentiate their teaching methods so they can promote their students' individual growth. In addition, when analysing the profiles of eight support-need latent variables, the teachers in the different countries viewed supporting students' holistic development as the most important area. In summary, Harju and Niemi conclude that new teachers' needs are related to their students' learning and well-being, but in order to respond to these student-related tasks teachers need partnerships in the school community as well as partners outside the school environment. Cooperation with parents, special needs teachers, and often also with multi-professional experts, is needed. To resolve conflict situations and address students' individual and holistic growth, teachers need partners and the opportunity to work with different kinds of experts and stakeholders. Teachers' work is not limited to the classroom. Nowadays, it increasingly expands outside the classroom and the school environment.

The article in the Varia section, "Pre-service Home Economics Teachers' Attitudes on Selected Aspects of Practical Teaching”, by Francka Lovšin Kozina, is also related to teacher education. This paper presents the results of a study conducted among pre-service home economics teachers in a Slovenian context. The results showed that the majority of the pre-service teachers agreed that the feedback from their colleagues was helpful for their professional development. Collegial interaction is important in professional development, and it has an impact on the teacher's intention to continue a career in education. However, the results also revealed some critical points in a teacher's competency development, including problems related to the application of theoretical knowledge on the children's development in practice and problems related to classroom management in specific situations. Interestingly, pre-service teachers with more teaching lessons showed less confidence in knowing the developmental characteristics of the children for whom they must prepare lessons. It can be assumed that pre-service teachers and new teachers have similar problems: both are faced with inconsistencies between their ideals about teaching and their 
initial teacher experience. These findings can also suggest a gap between preservice teachers knowing the facts related to the children's personal development, and the student's ability to apply factual knowledge, which also suggests that some improvement is needed in the preparation stage of teaching practice. The results in the Slovenian context support Harju's and Niemi's study of newly qualified teachers in four European countries. The most important need that new teachers had for support was how to promote their pupils' development. When discussing partnership and interconnectedness, we can see that, from a teacher's viewpoint, the closest sphere of interaction is the students in the classroom, and teachers need resources to address that.

The second article in the Varia section is "Recognition in Programmes for Children with Special Needs". Marjeta Šmid examines the factors that affect the inclusion of pupils in programmes for children with special needs. She uses the theory of recognition as a frame for their analysis. The concept of recognition includes three aspects of social justice: economic, cultural, and political. The author argues that not only institutional arrangements but also patterns of cultural values prevent children with special needs from enjoying equal participation in the school's social life. She notes that, in practice, arrangements of schooling and the treatment of children with special needs prevent them from full participation in the life of the classroom and the school. Šmid argues that, if pupils with special needs are to actively participate in the classroom and advance their achievements in schools, redistribution (additional resources, change of methods of work), recognition (change of oneself, attitudes and values) and better representation (participation in the widest possible activities, actual decision-making, children are heard) are needed. Moreover, we must also be aware of which cultural patterns of values hinder children with special needs from equal participation and how those cultural patterns of values impact these children.

This issue of CEPS Journal also includes a short reflection about the theme of the TEPE conference. In his report, "Building partnerships by bridging cultures, contexts, and systems - Reflections on TEPE 2015", Marco Snoek notes that we need a stronger analysis of the dynamics and conceptual elements of partnerships. Building a partnership is not about integrating two subsystems into one; nor is it about making formal agreements and establishing criteria that need to be met if one is to be considered as a partner in a partnership. Rather, building a partnership entails creating spaces for a shared professional dialogue where participants from different subsystems meet, exchange their understanding and interpretation of issues and create opportunities for mutual learning based on mutual respect. 
This issue of the journal provides examples about partnership at different levels of the educational ecosystem. The articles describe macro-level national processes, institutional practices, and personal, micro-level experiences. We can see that the system can lose its functionality and resilience if some of the actors take control and exert their power and authority, and if communication only flows in one direction as a top-down strategy. We can also see that professional support and collegiality are important resources, and in changing contexts we must re-evaluate what is truly beneficial for learners, as in the case of inclusion. In an educational ecosystem, we cannot wait for some outside forces to form a partnership. Even in biological ecosystems, there are always actors, even though the actions are not strategically designed. Human ecosystems are led, intervened and developed by human actions. Our increasingly complex and dynamic world sets high demands for all actors in the educational ecosystem. We must be aware of how different actors influence the system. We must identify the barriers and obstacles that should be overcome. In an educational ecosystem, partnership involves intentional action. It demands that we identify, analyse and manage educational systems and their subsystems. We have to go beyond rhetoric and analyse how power, rights, and responsibilities, control, regulation and resources are negotiated and agreed upon. Teachers' work depends on macro-level systems as well as institutional cultures, but they are also actors who influence those systems and processes. To maintain a healthy and successful educational ecosystem, interconnectedness and communication are essential.

\section{HANNEle Niemi}

\section{References}

Cole, M. (1991). Conclusion. In L. B. Resnick, J. M. Levine, \& S. D. Teasley (Eds.), Perspectives on socially shared-cognition (pp. 398-417). Washington, DC: American Psychological Association. Council of the European Union, Council conclusions of 20 May 2014 on effective teacher education. Official Journal of the European Union 14.06.2014, C 183/22-24. Habermas, J. (1987/89). Theory of communicative action. Volume 2: System and Lifeworld: A Critique of Functionalist Reason. (T. McCarthy, Trans.). Boston: Beacon Press.

Kahn, L. H., Monath, T. P., Bokma, B. H, et al. (2012). One Health, one medicine. In A. Aguirre, R. Ostfeld, \& P. Daszak (Eds.) New Directions in Conservation Medicine: Applied Cases of Ecological Health (pp. 33-44). New York: Oxford University Press.

Mars, M., Bronstein, J., Lusch, R. (2012). The value of a metaphor: Organizations and ecosystems. Organizational Dynamics, 41(4), 271-280.

Moore, J. F. 2006. Business Ecosystems and the View from the Firm. The Antitrust Bulletin, 51(1), 31-75. 
Oksanen, K., \& Hautamäki, A. (2015). Sustainable Innovation: A Competitive Advantage for Innovation Ecosystems. Technology Innovation Management Review, 5(10), 24-30.

Niemi, H., Multisilta, J., Lipponen, L., \& Vivitsou, V. (Eds.) (2014). Finnish Innovations and Technologies in Schools. Towards New Ecosystems of Learning. Rotterdam: Sense Publishers. Reynolds, R. E., Sinatra, G. M., \& Jetton, T. L. (1996). Views of knowledge acquisition and representation: A continuum from experience centered to mind centered. Educational Psychologist, 31(2), 93-104.

Säljö, R. (2010). Digital tools and challenges to institutional traditions of learning: technologies, social memory and the performative nature of learning. Journal of Computer Assisted Learning, 26(1), 53-64.

Säljö, R. (2012). Schooling and spaces for learning: Cultural dynamics and student participation and agency. In E. Hjörne, G. van der Aalsvoort, \& G. Abreu (Eds.), Learning, social interaction and diversity - Exploring school practices (pp. 9-14). Rotterdam: Sense.

Schwinda, J., Gilardia, K., Beasleyb, V., Mazeta, J., \& Smitha, W. (2016). Advancing the 'One Health' workforce by integrating ecosystem health practice into veterinary medical education: The Envirovet Summer Institute. Health Education Journal, 75(2), 170-183.

Vygotsky, L. S. (1978). Mind in Society: the development of higher psychological processes. Cambridge, MA: Harvard University Press.

Walpole, S. C., Pearson, D., Coad, J., \& Barna, S. (2016). Medical Teacher, 38(4), 338-356. 